\title{
IMAGE BUILDING THROUGH EFL TEXTBOOK 'MY PALS ARE HERE' TO STUDENTS IN KUPANG, EASTERN INDONESIA
}

\author{
Peggy Jonathans \\ Faculty of Teacher Training and Education, Artha Wacana Christian University, Kupang, Indonesia \\ E-mail: jonathanspeggyofficial@gmail.com
}

APA Citation: Jonathans, P. (2018). Image building through EFL textbook 'My Pals are Here' to students in Kupang, Eastern Indonesia. Indonesian EFL Journal, 4(2), 63-70. doi: 10.25134/ieflj.v4i2.1377.

\begin{abstract}
English textbook is supposed to display society traditions and civility to encourage intellectual conversation among students. Even at earliest stage, young students can grow thoughtful principles of living in diversity and respectful among multicultural and religious community. The heart of moral values in students' English book is expected to effectively address social and moral problems of society and to maintain the harmony of living. 'My Pals are Here' English textbooks for primary schools, presents EFL/ESL Asia themes. This motivates one private primary school in Kupang, eastern Indonesia to use this book believing that their students are part of international and wider community and engaging them in more Asia perspectives with attractive and colorful world teaching them many good values. By elaborating humanistic approach in the book content, this book achieves to deliver daily issues encountered by Asian children living more progressively with the introduction of many discourses in Asia and beyond without such pigeon holed the context of the book to very narrow scope. This discussion paper therefore aims to look at and discuss the input established within the book through the language and topic contents, as well as social and cultural values underlying the content, and the virtues addressed to the children. Images built within this book depicted through illustrations, figures, negotiation of meanings and interaction which extensively encouraged and performed from tasks given. The textbook succeeds to show self-identity of Asia throughout the content.
\end{abstract}

Keywords: Language Content; Subject Content; Moral Values; Images.

\section{INTRODUCTION}

In designing learning materials, the background of targeted students and their contextual needs should be accommodated through their subject textbook as this helps learning becomes meaningful and relevant. 'My Pals are Here' published by Maxwell Limited (2004) is one collection of Mentari books, designed for grade 1 up to grade 6 for elementary school of Asia which combines both notional as well as situational syllabus. According to Setiyadi (2006, p. 16), the first syllabus type consists of a collection of functions or notions to perform in the English lesson; whereas the latter type is about imaginary situations used for learning the language. Within notional and functional syllabus, communicative functions are selected and logically ordered to the students' needs and the learning materials written referring to this approach will elaborate experiences, intuitions and common senses. As in complementary to functional approach, situational approach takes real world situations with three factors come into play including participants, setting and communicative goals (Cunningsworth, 1995, p. 57). This textbook written in English for beginner level, accompanied with exercise book called as 'workbook' for each grade comprises of averagely 8 up to 12 topics, for example, selfintroduction, neighborhood, people on street, pet, animals at wild, roles of family members, dreams and ambitions. Students doing the exercises will have direct clues from the textbook such as color association, picture illustration, sequenced pictures, rhymed poem, 
funny sound reading and useful vocabulary. Translation is least encouraged as the book tries to bring the students' mind into English thinking on their level and beyond. Broad themes are introduced before several related topics. Cultures, ethnicities, religion, traditions of Asia are addressed within the language contents so students' learning complexity is merely coming from English language.

Role of textbooks should be more than skill exercises but further to serve life purposes. Risager (1990, in Cunningsworth, 1995 , p. 88) urges one of main responsibility of textbook is contributing towards cognitive mapping, by providing organized perspectives into culture and society; otherwise the skillbased subject would have no contents. Content analysis covers inquiry such as analysis on natural occurring language which aims of content analysis: to ensure objectivity, to see scientific methods which provide means to achieve systematic study, fulfillment of various scientific criteria including reliability and validity (Neuerdorf, 2002, p. 1). Further, he adds methods of content analysis in systematic and quantitative way by elaborating certain ways of analyzing and coding.

Krippendorf (2004) asserts that manifest content or latent of book through classification, tabulation and evaluation of its key symbols and themes is to ascertain its meaning and probable effects. Through this present writing, the writer will bring up how an ESL textbook My Pals are Here be engine of social and economic transformation in Asia context. My Pals are Here textbook is reflecting social structure, with pictorial constituents. Krippendorf (2004) claims that the ideas of messages serve specific purposes, and writing itself has predictable effects. What do texts in the book mean to students-users, and what do the texts and pictures enable or prevent the students from something, and what information carried by them does.

Neuerdorf (2002, p. 24) then recommends that latent content should manifest variables whereby the analysis can be conducted on written texts, transcribed speech, verbal interaction, visual images, characterization, non-verbal behaviors, sound events, any other message types. Accordingly, content analysis should be a summary analysis but an empirical analysis on content, e.g., making classification by sorting out the data from intensive coding on measured data. He emphasizes that valid coding in content analysis is essential made throughout training and substantial planning. As an academic endeavor, objectivity should be met at most cases in content analysis even no such thing really objective in social issue however the analysis must strive consistency among inquiries. The inter-subjectivity standard used in the context is to ask others whether they could 'agree on that something is true' rather than 'finding out objectively if something is really true'. Lasswell (1952 in Neuerdorf, 2002, p. 36) mentions that content analysis is technique aiming to describe with strict objectivity, precision and generality, on particular subject, in certain place at specific time. In addition, he mentions that some analyses aim to make predictive power within certain message areas instead of trying to answer theoretical importance.

The design of EFL/ESL textbooks for primary school students are more colorful, eye catching, and full of clues and hints as compared to higher level of students. Content analysis of this textbook will give academic implication of this practice of how textbook plays significant role addressing social values and norms to the students especially the young children. Sidek (2012) gives examples on the use of expository passages starting from elementary school in English in the first language (L1) setting will prepare students for the next school level and it is considered as best practice to expose them to content literacy by working with them, and this analysis will be good recommendation to other similar levels. In Indonesia, temporarily English is not listed neither as a compulsory nor elective subject for her elementary education. However, many local primary schools in the country due to the need of their students teach English and decide certain textbooks based on their own discretion.

In regards to classroom textbooks, Cunningsworth (1995) asserts that language contents operate at very complex stage and they need to be realized into smaller unit of lessons. He strongly recommends to reduce 
learning load for young students to be able to grasp it. Grammar aspects underlie the base of language contents. It is hotly argued whether form or use firstly introduced, although grammar plays essential role in language learning. He emphasizes that both must be learnt and as closely together as possible. This aims to make meaningful outcome of the grammar used and to contextualize the vocabulary in relevant settings. Therefore, it is stressed that exercises in textbook which sensitized learners to the structure of English lexicon and the various relationships exists. Global aspect of language also includes stress, rhyme, intonation, and the students' natural sounding of English approciacy will depend on their phonology skill and this is not transferable from their first language. Utterances will make sense which influenced by natural sound of their language.

In a child-centered lesson, Paul (2003, p. 28) urges that the children need to have support throughout the topic-based syllabus for fitting to their learning environment, relating to familiar themes, performing abilities and addressing meanings rather than forms. Imada (2012, p. 576) compares between American textbooks and Japanese, the first highlights theme of individualism such as self-direction and achievement whereas the latter highlights collectivism such as conformity and group harmony. Each of the cultural characteristics was also observed in picture content, attribution of the outcome, narrator, and role played. The study also indicated cultural differences in story characteristics. Rodriquez (2015, p. 167) found in an EFL textbook only static and congratulatory topics of surface culture and omit complex and transformative forms of culture, and this hinders students building more substantive intercultural competence in the language classroom. This therefore according to him, teachers need to address deep-rooted aspects of culture, so communication serves its purposes well addressing the targeted values and messages.

Some textbooks are pursued by national elites to pose political agenda through education. Textbooks can show economic, political, and mirror social reality (Xiangmei,
2016, p. 478). Some books are well noted for their textual description of certain communities and future expectations for better society. Images and additional modes for meaning making for children in learning EFL are necessarily important due to their limited capacity to understand abstract concepts and the messages sent by English textbook beyond their inferences. Moses (2015, p. 83) revealed that teachers' comprehensive knowledge about roles of images for bilingual learners can help their students by assisting them to scaffold language contents through images. She found that EFL young learners interacting with informational texts equipped with images can draw from their world while at the same time develop their vocabulary. Visual images, however, play indispensable pedagogical role in educating young learners (Leview et al., 1982; Carmey et al., 2002, in Xiangmei, 2016, p. 480). Social and cultural changes are reflected and roles of each member depicted from images presentation in each textbook.

In humanistic perspectives, effective learning is when students are engaged in learning process as 'whole' individual people, making choices, learning in meaningful contexts and in anxiety-free environment (Paul, 2003, p. 170), believing learning this way facilitates students to reach their full potential. The classroom book contents will do contribution to this virtue established within the students. Virtues are defined as admirable character traits and virtue ethics form of moral reflection which gives a central place to such traits of character. Arthur further adds that this approach includes a tolerance of ambiguity, an acceptance of one self and others, having peak experience leading to personal transformation through new personal insights. These can be exercised by providing the students to ideal discourse, e.g. textbooks, to make them part of their world by interchanging views, building mental model of English, encouraging the students to handle conflict and respecting each other regardless the background attachments. Because intellectual virtues-which are qualities of mind, are not inborn, yet need to be trained to young learners to act accordingly. Kupperman (1991, p. 16-17, in Arthur, 2003, p. 33) claims that moral education cannot 
merely be a series of rational appeals. This implies that the affection aspects of the students should be assisted by teachers and textbooks. Delivering textbooks to students with this in mind allows teacher to teach the students to deal with real complexity of living. Students are endowed with temperamental and biological disposition which determine, along with the way of how they are brought up and exposed to social contact, this helps them to learn making decision (Arthur, 2003, p. 29). Having this on mind, the study is interested to analyze textbook content under a topic 'Image Building through 'My Pals are Here' to EFL Students in Kupang, Eastern Indonesia', motivated by two questions:

1. What is the language content delivered in the textbook, in terms of grammar use, vocabulary, and integration of pronunciation?

2. How are images of Asian life realized in the topic and subject content as well as the social and cultural values?

\section{METHOD}

This study is designed as descriptive method. The subject as the heart of the study is EFL textbook, My Pals are Here, published by Maxwell Limited (2004), in cooperation with Mentari book collections. Taking 4 packages of books, each consists of a student book and a workbook, the book number $1 \mathrm{~A}, 1 \mathrm{~B}, 2 \mathrm{~A}, 2 \mathrm{~B}$ taken as the purposive sampling, out of 6 in total. Purposive sampling technique has been vital, although this cannot be generalized, but the concern lies on the goal to acquire in-depth information from the source (Cohen et al., 2007, p. 114-115). In addition, they view that this sampling technique on the basis of their judgment of their typicality or possessions of the particular characteristics being sought.

This selection is based on the gradual transition of the books' topics and level of English, since the first four books (1A-2A) are essentially important to progressively develop the pupils' basic English as second or foreign language. The instrument then is called documentary, because the primary data was taken from the printed sources. Interpretations and discussion are orientating to positive images established within the contents.

\section{RESULTS AND DISCUSSION}

The language content of the textbook: Grammar use, vocabulary, and integration of pronunciation

The textbook My Pals are Here mostly use basic grammar, i.e., Present Tense and simple past for Grade 1 up to Grade 4 primary school. This simple form is at the appropriate level for the students, delivered in short sentences and the language is very direct with explicit meanings. The vocabulary coverage is also graded and has color clues e.g. object around them including animals sound and plants. The list come from the students' special interests, e.g. hobbies, sports, games, happy holidays. To add this book complexity, students explore new words and the context connection in sequence such as family time, fairy tales, folklores and outer space. As the difficulty levels increase, the vocabulary for pre-cautions and rule for public have been addressed and well organized with pictures aids to understanding. There is a clear association between pictures and words to send meanings to students, with some additional sounds of animals or objects to complete the onedimension picture in the book as if representing the whole living things in the environments.

The tenses used by the textbook writers are highlighted by different colors to indicate different point to the students without complicated explanation to the students, very brief and quite eye catching. The simple past tense is used in the units of the book $1 \mathrm{~A}$ and 1B with some examples provided allow the teachers as well as the students themselves to extend to other sentences production. Another grammar point, imperative, come into play. The students have been familiar with orders and instructions in real life and this form stimulates their schemata knowledge to utilize the pre-notions into learning English in formal situations. This linking knowledge has been practiced by the book and very ideal for any other English lessons.

Pronunciation in 'My Pals are Here' begins with rhyming words in short poems, songs with repeated chorus and short passages. The 
size of the materials for pronunciation is quite small but the consequencing materials on pronunciation keep closely related in topics. Negotiation of meanings in these contexts takes place. The students will then be excited to pronounce the words with purpose and in meaningful ways.

\section{The topic and subject content and social and cultural values}

The discourse of My Pals are Here depicts Asian modern life with many good values and positive attitudes, including environment and animals caring, enjoying life through sports and games, fostering imaginative skills, encouraging dreams for future, gender awareness, safe zone for young children, fair play and healthy competitions.

One of trending issues in global and local scope is gender awareness. Several figures in the book address gender equality in household, take for example, in one illustration in Book $1 \mathrm{~B}$, a father grills sizzles with hot pan while a mother is cooking noodle mie in burning stove. The children look happy while waiting for the food on the dining table for their parents preparing meals. This is very different from Indonesian textbook which tends to discriminate women as the house chores bearer and children carrier in addition to the overwhelming domestic responsibilities, while the spouse (men) at the same time can get relax reading for newspaper or just waiting on the table together with the kids. Gender issue is also addressed in family holiday, where both mom and dad can relax with the children, for example, on the beach, a mom can be so relaxing enjoying the family holiday without being asked more extra task in attending the kids, but her partner in turn will look after the kid. Such an ideal family where responsibilities are shared and the two deserve holiday or vacation after tiring work at home and office. Children in the illustration seem to enjoy being with their parents spending time with them at home and outside, which this book represents as the common picture of the society. As far as my observation, many Indonesia EFL textbooks leave untouched this gender issues. Further, this textbook highlights boys and girls at schools being encouraged to compete in fair play or sports and games. No restriction at all and pigeon holes on certain games based on the sex of players.

Deep down to the whole aspects related to community, English textbook writers should thoughtfully consider multi-faith and multiethnicity contexts where the students exist within. Being insensitive to this discourse can mislead the children at their golden ages which considered as the crucial foundation for their later life. Thus a book review is essential before releasing any EFL textbooks to public. With such open-minded attitudes, 'My Pals are Here' gives credits to all residents by simply mentioning their names, e.g., Indian heritage name (Raju), Chinese ethnicity (Mr. Li), and other tribe (Mr. Ahmad), Malay, or Moslem name. Pictures of these men in garden or agricultural sector vividly are shown without ranking each ethnicity to different level of jobs (higher versus lower). Indonesia EFL textbooks, on the contrary, tend to ignore that Indonesia consists of many tribes and people with various backgrounds, and to worsen the situation, they are not represented well by those publishers. This book, however, brings positive message that everyone can be great in any sectors of economic despite their background, e.g., farming. $\mathrm{Mr}$. $\mathrm{Li}$ and $\mathrm{Mr}$. Ahmad as previously mentioned, in this regard are of two different ethnicities in Singapore but share of the same passion. This indicates members of community are not discriminated for their jobs. Beside ethnicity names, foreigners' names also draw this research interest, i.e., de Cruz family, which have been permanent residents in the country (Singapore per se) and are being acknowledged. This textbook internalizes modern perspective that being Asian means being global citizenship and acting accordingly. Raju, an Indianheritage-sound name mentioned in Book 1B, lives with four family members of the same ethnicities in a modern Asian household where the house is fully equipped with modern appliances. This condition erases such hegemony of Asian being in line of poverty but nowadays they progress more in their way of life comparing to the past. This does not mean ignoring the poverty happens around, yet 
the writer tries to put everything in balanced for better perception to the young students.

Along with this, interfaith communication appears in the content. One figure mentions Christmas celebration, being announced in a newspaper article with brief reading passage, entitled 'a Christmas event in Orchard Road'. The children learn to respect other religions despite the differences among them. Objectivity in designing the content makes all children belong to the discourse delivered, without leaving any students left behind unacknowledged. The reading passage continues to Chinese and Singapore Moslem folklore written in interesting setting. The passages present multicultural and multifaith society, each in its setting but all stories are important to listen to.

One important issue also put forwards is environment. The book illustrates happy fish in sea while a speed boat is running close to the fish. Similar to Australia, this book promotes and shares the idea of safe and friendly environment in public and open areas for men as well as for animals in Asian countries. Learning this concept early educates the young students and forms their attitudes toward wildlife.

This book further tries to highlight different aspect of the children life in many developed countries. To some, it is a new positive practice in one culture to have a family discussion with the whole family members to decide family's vacation to a certain place. This child-friendly family habit opens the pupils horizon that family should hear young children voices. The concept of family holiday outside the living area or far away destination in this book contextualizes that holiday has become essential need for modern family, aiming not only to create closer relationship among family members but also to refresh family and improve their daily life quality. Although to this point, on the other part of the world, many children still suffer due to overload domestic tasks and poverty, but this book attempts to put everything in proper position, emphasizing that children must have rights to experience fullness in their childhood, and sports and games have been the tools for children to express themselves at their potentials.

Children sometime meet taboos, controversies issues, legend, myths and stereotypes. Dealing with these, the book provides various texts to help them understand those things and logically can differentiate facts from imaginations. This makes them better people in their society to act according to their sincere conscience as they get used to which are logic, good for everyone, polite, acceptable, respect and just.

Learning EFL means learning the culture to add the sense to the language. Having pets at home, is probably a common thing to some, especially taking the pet as close friend. However, the context of pet could be awkward to others. Instead of a pet, in one figure in Book 2A, a boy grows a cactus at home, but his parents get so angry when he forgot to bring it outside as the plant got bigger and caused a problem to the family. This normally happens when the children lack of responsibilities of taking good care of their pets or favorite plants. This figure at the same time talks about the pet culture and teaches discipline and responsibility. This motivates hobby and responsibility are two inseparable aspects.

Realizing that the children are part of the universe, this book further brings very modern and sophisticated topic such as outer space. Learning astronomy would motivate the children creating their future dreams such as becoming astronauts. They can think of making pollution-free environment and saving endangered ozone. After the planets topics, the book moves to the world of imagination. Children grow a lot the cognitive domain through the world of fantasy. They need to experience of fairy tales and explore imaginative creatures beyond real times. This boosts the students' visualization skill towards their concrete world.

At the end of the book, the children learn public rules and manners as well as social skills, to properly be accepted as the public talking in public area are integral part of this book. The book plays as social tool transforming members. Topic regarding crossing on the street and the safety and 
manner of the citizens including the young members of society that everybody should behave accordingly for the harmony of all. Acting based on rules and manners teaches them behaviors of civilized community and respect attitudes. Many in Indonesia tend to be insensitive talking in public zones. For the comfort of all, children should learn to lower their volume. This seems insignificant topic to bring up to the conversation but then many people these days forget to concern about this and as consequence cause problems to interpersonal relationship and to others' discomfort. Many other topics, like driving bikes, whispering, manner of eating are put into perspective as training the kids to have their pure conscience in their civilized and modern community and to lead them into proper behaviors.

The children at schools should also understand that wearing swimsuit in beach or swimming pool are common things and they should learn because in many public pools prohibition for other swimmers not wearing them due to security reasons. Mostly many Indonesia publishers for English textbooks restrict themselves to talk to this area stereotyping this as pornography. Usually they just show the swimsuits without the person who are wearing them. However, My Pals are Here illustrator draws it very clear and colorful swimsuit as part of sport and recreational activities and the students can have the whole comprehensive picture of what is swimsuit and location the swimsuit belongs to. This one-dimension picture successfully sends the messages to readers the real-life representation of the sport 'swimming' and ideas related to that.

Logically this book has been facilitating the students to be independent in public areas, for example, to go to toilet or to certain facility, in their opportunity going somewhere with the family, at least they know how to find direction of a map or board of notice. The children are taught in using mapping skills in public area to survive if they get lost or need to return to their parents. Although this does not mean to replace the parents' responsibilities, the children have been trained to survive in any unexpected circumstances. The children, on the other hand, are trained to be independent to go toilet or nearby facilities although still under the parent supervision.

In under-developed or developing countries, child labor issue is of regular news. Eradicating this bad practice requires all parties to work hard. Different from developed countries, children can also get extra money from part-time jobs offered during school holidays or summer. This culture can be introduced to the children but showing that their parents should send them to schools for their education rights. The children not only learn to be independent but also skillful in doing small chores around house and neighborhood that gives them the jobs. Through this reading, they understand how to collect extra money and grow to be independent.

Helping or caring for friends is also part of the values this book delivers. In fair play and competitive atmosphere, solidarity and healthy competition is taught through the exercise. The children see clear pictures of sports and story after the sports, a friend helps a wounded player and they went home with happy feeling. This teaches the children that competition should not end in quarrel or conflicts but close with empathy for the wounded friends. This will build within the children the integrity of personality traits in their adulthood and sportive acts dealing with defeat versus victory. This picture encourages the students of paying positive attitudes towards others on bad times.

\section{CONCLUSION}

This research report paper concludes that language content of this textbook covers very practical topic such as color, hobbies, games, sports, space adventure, holiday, folklore, nature (wildlife and plants). The grammar used is present tense and smooth transition happens with different structure, past tense for the students to be familiar with dynamic of English language. New vocabularies in segments to add the complexity of the book slowly are addressed within the units. The integration of pronunciation is created by simple transcript the young students can identify and use as model for pronunciation, in 
addition to the teacher's assistance in using the words clearly pronounced and used in context. The exact pronunciation is not prioritized at the first place. Further, the images of Asian life within the topics and subject contents cover Asian discourses and worldwide issues such as festivals, values of the community (the social and cultural values), diversity in beliefs and religion, inventions of technology and facilities addressed to the students.

In conclusion, five important things to highlight of this study as follows:

a. EFL teachers in Indonesia are supposed to have open-minded attitudes. They need to teach with global perspectives but with local touching. This will help them bring the idea of world community to their students as very dynamic, modern, and safe place to live

b. EFL textbook writers for Indonesia schools should realize that Indonesia consists of many ethnicities, religions, backgrounds and cultures. The EFL textbooks and the like should not be used as political tool to change the rich property of the country and to exercise power but indeed to highlight the differences as rich diversity to color the country. Any false or misleading contents in the book are very dangerous for the young learners to internalize wrong values. Their information intake in early years will be the foundation for later life.

c. Indonesia government particularly the education authority in districts and local area should work together to exercise both the positive Asian values and cultures and amazing Indonesian ones but do not limit the books into certain values of the country.

d. School administration of many schools in NTT province are encouraged to use "My Pals are Here" as main reference for their EFL course in addition to their modified handout because the students should be prepared to be global citizens with such integrity attitudes whose discourse provided in this textbook. e. Parents would be glad if their children have global and modern perspectives dealing with any aspects of their life. They are not pigeon holed but trained to be civilized through the book content. Any books similar to this one are good for parents to spend time with their children for discussion and exercise new constructive and useful tradition at their home, such as family meeting for any family plans, survival skills, pet responsibilities, parttime job, etc.

\section{ACKNOWLEDGMENT}

High appreciation is addressed to Tunas Bangsa primary school in Kupang and the teachers who shared their stories about the reasons behind of using this textbook and challenges when introducing the discourse to the EFL pupils. Valuable contribution was also shown by one of the students, Alicia Mondolang, for her frank and genuine opinions when the writer worked with her throughout this book, to have her perception on the contents. This research was accomplished by the financial support of Research Centre of Artha Wacana Kupang, conducted under 2018 Internal Scheme.

\section{REFERENCES}

Arthur, J. (2003). Education with character: The moral economy of schooling. New York: Routledge Falmer, Taylor and Francis Group.

Cohen, L., Manion, L., \& Morrison, K. (2007). Research methods in education ( $6^{\text {th }}$ ed.). London \& New York: Routledge Taylor and Francis.

Cunningsworth, A. (1995). Choosing your coursebook. Oxford: Macmillan Heinemann.

Krippendorf, K. (2004). Content analysis: An introduction to its methodology ( $2^{\text {nd }}$ ed.). London $\&$ New Delhi: Sage Publications, Inc.

Moses, L. (2015). The role(s) of image for young bilingual reading multimodal informational texts. Language and Literacy, 17(3), 82-99.

Neuerdorf, K. A. (2002). The content guidebook. London \& New Delhi: Sage Publications, Inc.

Paul, D. (2003). Teaching English to children in Asia. Hong Kong: Pearson Education Asia Limited.

Sidek, H. M. (2012). EFL textbook analysis. Language and Literacy, 14(3), 27-45. 